\title{
Duration of Dual Antiplatelet Therapy and Late Stent Thrombosis Following Percutaneous Coronary Intervention with Second-Generation Drug-Eluting Stents: A Simple Meta-Analysis of Randomized Controlled Trials
}

Bei-you Lin · Ping Li · Peng Wu • Ri-na Jiang • Pravesh Kumar Bundhun •

Mohamad Anis Ahmed

Received: July 25, 2019 / Published online: September 18, 2019

(C) The Author(s) 2019

\section{ABSTRACT}

Introduction: The aim of this simple metaanalysis was to systematically compare the occurrence of late and very late stent thrombosis with a short versus a longer duration of dual anti-platelet therapy (DAPT) use following the implantation of second-generation drugeluting stents (DES).

Methods: Randomized controlled trials that compared short- and long-term DAPT use following percutaneous coronary intervention (PCI) with DES and that reported late ( $>30$ days but $<1$ year) and very late ( $>1$ year) stent thromboses were searched from the bibliographic database of life sciences and biomedical

Enhanced Digital Features To view enhanced digital features for this article go to https://doi.org/10.6084/ m9.figshare.9767168.

B. Lin · P. Li $(\bowtie) \cdot$ P. Wu · R. Jiang

Department of Cardiology, The First People's

Hospital of Yulin and The Sixth Affiliated Hospital

of Guangxi Medical University, Yulin, Guangxi,

People's Republic of China

e-mail: gxliping@126.com

P. K. Bundhun

Department of Internal Medicine, The First

Affiliated Hospital of Guangxi Medical University,

Nanning, Guangxi, People's Republic of China

M. A. Ahmed

Department of Cardiology, Peking University

People's Hospital, Beijing, People's Republic of

China information, which is also known as MEDLINE, as well as other searched databases including EMBASE, the Cochrane Central and http:// www.ClinicalTrials.com. Statistical analysis was carried out using RevMan software [odds ratios (OR) and 95\% confidence intervals (CIs) represented the results].

Results: This simple analysis consisted of five randomized controlled trials with a total of 7142 patients. The current results showed no significant difference in late stent thrombosis associated with a shorter or longer duration of DAPT use (OR 0.98, 95\% CI 0.30-3.18; $P=0.97$, $\left.I^{2}=0 \%\right)$. The result for very late stent thrombosis was also not significantly different (OR $0.30,95 \%$ CI $0.03-2.95 ; P=0.31$ ).

Conclusions: This simple analysis showed no impact of DAPT duration on the occurrence of late and very late stent thrombosis. Similar late and very late stent thrombosis rates were observed with 6-month versus 12-month duration of DAPT use following PCI with second-generation DES.

Keywords: Cardiology; Coronary angioplasty; Dual antiplatelet therapy; Late stent thrombosis; Second-generation drug-eluting stents

\section{INTRODUCTION}

Today, percutaneous coronary intervention (PCI) with drug-eluting stents (DES) is preferred 
in patients with cardiovascular diseases (CVD) because of its association with decreased infarct size, re-occlusion, lower angiographic restenosis rates and reduced mortality. Unfortunately, although made with new materials and designs, DES is often associated with the occurrence of late stent thrombosis [1]. Apparently, stent thrombosis is dependent on two main factors: the type of stent used and the total duration/ discontinuation period of the antiplatelet regimen following coronary stenting.

Compared with the first-generation DES, second-generation DES with their novel designs and materials and better anti-proliferative agents have proved to be associated with significantly lower stent thrombosis rates [2]. However, due to the small existing probability for stent thrombosis following PCI, standard dual antiplatelet therapy (DAPT) with aspirin and clopidogrel is still used as a preventive measure [3].

Guidelines based on the treatment strategy following PCI were recently published by the American Heart Association and the European Society of Cardiology [4, 5]. Nevertheless, even though these guidelines are acceptable and have been thoroughly followed, only a few studies have been based on the comparison of late stent thrombosis in patients who were exposed to a short-term (6 month) versus longterm (12 month) duration of DAPT use following PCI with DES, and it is not clear whether late stent thrombosis is significantly reduced with the long-term use of DAPT.

Through this simple meta-analysis, we aimed to systematically compare the occurrence of late and very late stent thrombosis with short- versus long-term DAPT use following second-generation DES implantation.

\section{METHODS}

\section{Searched databases and searched strategy}

'Dual anti-platelet therapy and percutaneous coronary intervention,' 'long-term clopidogrel use,' 'short- and long-term duration of dual antiplatelet therapy,' 'long-term dual antiplatelet therapy,' 'duration of dual antiplatelet therapy,' 'duration of clopidogrel' and 'long-term clopidogrel use and stent thrombosis' were the key terms searched for on the online electronic databases.

Participants were drawn from relevant English publications through electronic databases (using the above-mentioned terms and phrases). The publications satisfied the following inclusion and exclusion criteria (Fig. 1):

\section{Inclusion Criteria}

(1) Studies categorized as randomized controlled trials; (2) trials that compared short- and long-term DAPT use following PCI; (3) trials that involved the implantation of second-generation DES; (4) DAPT involving specifically aspirin and clopidogrel; (5) trials whereby late and very late stent thromboses were reported.

\section{Exclusion Criteria}

(1) Studies that were non-randomized controlled trials; (2) studies that did not involve DES implantation; (3) studies in which late and very late stent thromboses were not reported; (4) studies that were not based on the duration of DAPT use; (5) studies that involved another drug in place of clopidogrel, e.g., ticagrelor or prasugrel; (6) repeated studies.

\section{Outcomes, Types of Participants and Duration of DAPT Use}

Acute, sub-acute, late and very late stent thromboses were the outcomes reported in the selected studies. However, in this analysis, only late ( $>30$ days but $<1$ year) and very late ( $>1$ year) stent thromboses were assessed (main clinical end points). Acute and sub-acute stent thromboses were not assessed since late stent thrombosis was considered a more important complication of DES.

The participants were patients with coronary artery disease or acute coronary syndrome and were undergoing PCI with secondary DES. All the patients received aspirin and clopidogrel prior to and continually after the invasive procedure, as shown in Table 1. 


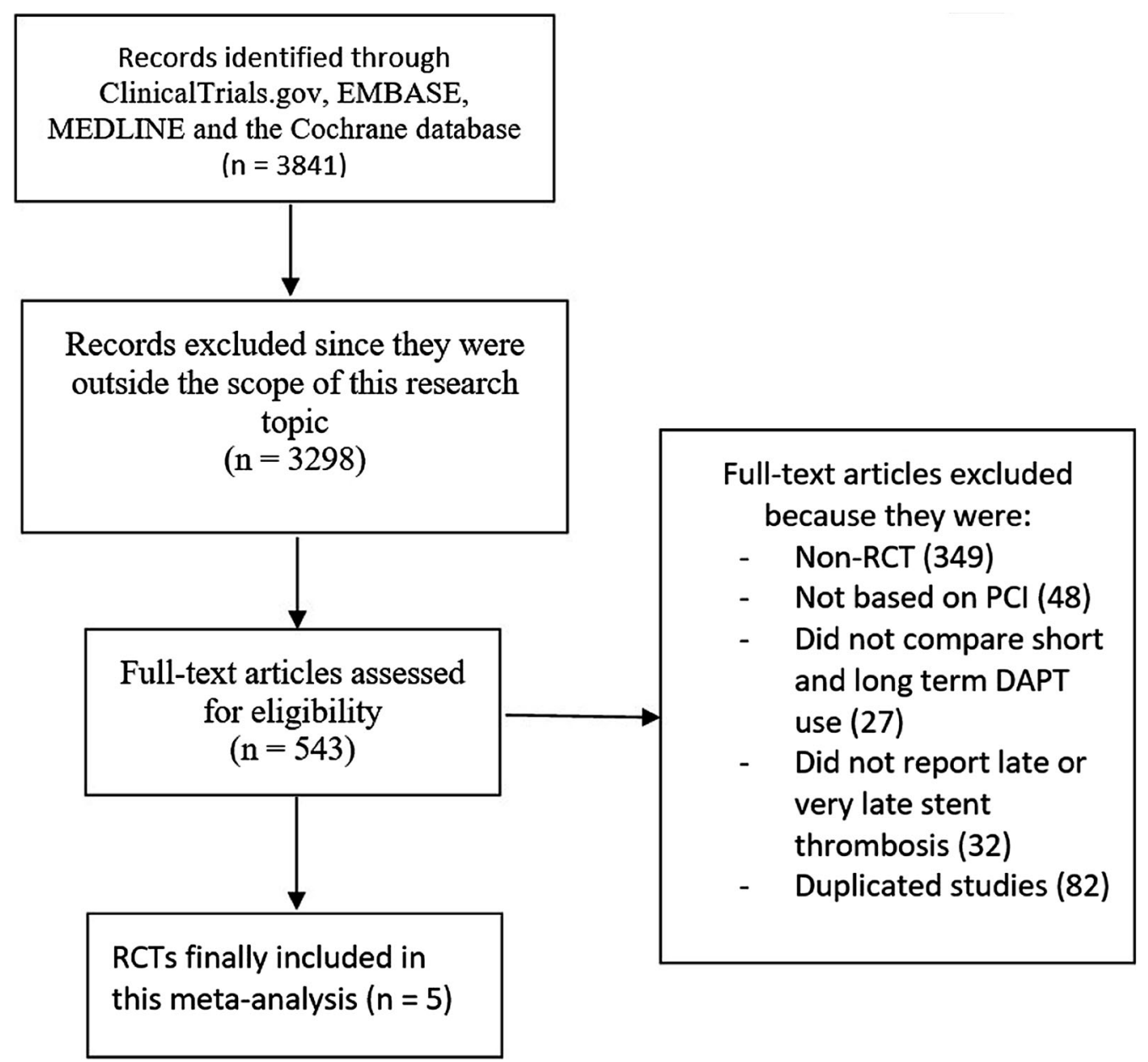

Fig. 1 Study selection represented through this flow diagram

Duration of short-term DAPT use was 6 months and of long-term DAPT use was 12 months (Table 1 ).

\section{Data Extraction and Review}

Six authors independently participated in the data extraction process. The participants were classified into the short- and long-term DAPT groups, respectively. The baseline features of the subjects, total late and very late stent thrombotic events, methodologic features, duration of DAPT use and information related to the implanted DES were all extracted.

The methods used in the trials were assessed (Cochrane Collaboration) [6]. Grades were allotted (grade A, B and C represented low, moderate and high risk of bias, respectively).
Any disagreements that followed while extracting data and during the assessment of the trials were resolved by consensus.

The Preferred Reporting Items in Systematic Reviews and Meta-analyses (PRISMA) study guideline was followed for this meta-analysis involving randomized controlled trials [7].

\section{Statistical Analysis}

This is a simple meta-analysis of randomized controlled trials. RevMan 5.3 software (latest version) was used for the analysis of data and then represented by the odds ratios (OR) and 95\% confidence intervals (CI). Heterogeneity was assessed by (1) the Q statistic test and (2) the $I^{2}$ statistic test. As described by the statistics rules, $P \leq 0.05$ was considered significant. In 
Table 1 Outcomes, follow-ups and types of participants

\begin{tabular}{|c|c|c|c|c|}
\hline Studies & Outcomes & Types of participants & $\begin{array}{l}\text { Short-term versus long- } \\
\text { term DAPT use }\end{array}$ & $\begin{array}{l}\text { DAPT } \\
\text { components }\end{array}$ \\
\hline $\begin{array}{l}\text { I LOVE IT } 2 \\
\text { [8] }\end{array}$ & $\begin{array}{l}\text { Acute, sub-acute, late and } \\
\text { very late ST }\end{array}$ & $\begin{array}{c}\text { Stable CAD and ACS } \\
\text { undergoing PCI }\end{array}$ & 6 versus 12 months & $\begin{array}{l}\text { Aspirin and } \\
\text { clopidogrel }\end{array}$ \\
\hline $\begin{array}{l}\text { IVUS-XPL } \\
\text { [9] }\end{array}$ & $\begin{array}{l}\text { Acute, sub-acute and late } \\
\text { ST }\end{array}$ & $\begin{array}{l}\text { CAD patients undergoing } \\
\text { PCI }\end{array}$ & 6 versus 12 months & $\begin{array}{l}\text { Aspirin and } \\
\text { clopidogrel }\end{array}$ \\
\hline $\begin{array}{l}\text { OPTIMA-C } \\
{[10]}\end{array}$ & $\begin{array}{l}\text { Acute, sub-acute and late } \\
\text { ST }\end{array}$ & $\begin{array}{l}\text { CAD patients undergoing } \\
\text { PCI }\end{array}$ & 6 versus 12 months & $\begin{array}{l}\text { Aspirin and } \\
\text { clopidogrel }\end{array}$ \\
\hline RESET [11] & Sub-acute and late ST & $\begin{array}{l}\text { CAD patients undergoing } \\
\text { PCI }\end{array}$ & 3 versus 12 months & $\begin{array}{l}\text { Aspirin and } \\
\text { clopidogrel }\end{array}$ \\
\hline $\begin{array}{l}\text { SECURITY } \\
{[12]}\end{array}$ & $\begin{array}{l}\text { Sub-acute and late and very } \\
\text { late ST }\end{array}$ & $\begin{array}{l}\text { Diabetes patients } \\
\text { undergoing PCI }\end{array}$ & 6 versus 12 months & $\begin{array}{l}\text { Aspirin and } \\
\text { clopidogrel }\end{array}$ \\
\hline
\end{tabular}

$D A P T$ dual antiplatelet therapy, $S T$ stent thrombosis, $C A D$ coronary artery disease, $A C S$ acute coronary syndrome, $P C I$ percutaneous coronary intervention

addition, an increasing $I^{2}$ value denoted increasing heterogeneity. For this analysis, a fixed effects model was used during the statistical calculations.

Due to the small volume of studies, publication bias was correctly assessed and represented through funnel plots.

\section{Compliance with Ethics Guidelines}

This article is based on previously conducted studies and does not contain any studies with human participants or animals performed by any of the authors.

\section{RESULTS}

\section{Searched Outcomes}

A total of 3841 publications were obtained from the online databases (Fig. 1). After a prior assessment of the abstracts and titles, those publications that did not fit into the context of this research were eliminated (3298), with only 543 articles remaining.

The inclusion and exclusion criteria were applied to 543 selected articles as shown in
Fig. 1, and further elimination was carried out. Finally, only five randomized controlled trials [8-12] were included in this simple meta-analysis (Fig. 1).

\section{Main Features of the Trials}

As shown in Table 2, 5 randomized controlled trials involving 7142 patients (3556 patients with short-term DAPT use and 3586 patients with long-term DAPT use) were assessed. Second-generation DES such as zotarolimus-eluting stents (ZES) and everolimus-eluting stents (EES) were used.

After a fair assessment of the methods used, three trials were allotted grade ' $\mathrm{A}$ ' whereas two other trials were allotted grade ' $\mathrm{B}$ ' as shown in Table 2.

\section{Baseline Characteristics of the Participants}

Mean age of the patients, with a predominance of male participants, varied from 60.0 to 66.7 years (Table 3). Participants with comorbidities including hypertension, dyslipidemia and diabetes mellitus are listed in Table 3. 
Table 2 Main features of the trials

\begin{tabular}{|c|c|c|c|c|}
\hline Studies & $\begin{array}{l}\text { Total no. of patients with short- } \\
\text { term DAPT use }(n)\end{array}$ & $\begin{array}{l}\text { Total no. of patients with long- } \\
\text { term DAPT use }(n)\end{array}$ & $\begin{array}{l}\text { Type of DES } \\
\text { used }\end{array}$ & $\begin{array}{l}\text { Bias risk } \\
\text { grade }\end{array}$ \\
\hline $\begin{array}{l}\text { I LOVE IT } 2 \\
\text { [8] }\end{array}$ & 909 & 920 & BP-SES & A \\
\hline IVUS-XPL [9] & 699 & 701 & EES & A \\
\hline $\begin{array}{l}\text { OPTIMA-C } \\
{[10]}\end{array}$ & 683 & 684 & BES or ZES & $\mathrm{B}$ \\
\hline RESET [11] & 1059 & 1058 & ZES & A \\
\hline $\begin{array}{l}\text { SECURITY } \\
{[12]}\end{array}$ & 206 & 223 & $\begin{array}{l}\text { Second- } \\
\text { generation } \\
\text { DES }\end{array}$ & B \\
\hline $\begin{array}{l}\text { Total no. of } \\
\text { patients }(n)\end{array}$ & 3556 & 3586 & & \\
\hline
\end{tabular}

$D A P T$ dual anti-platelet therapy, DES drug-eluting stents, $R C T$ randomized controlled trials, BP-SES biodegradable polymer sirolimus-eluting stents, $O S$ observational study, EES everolimus-eluting stents, BES biolimus-eluting stents, ZES zotarolimus-eluting stents

Table 3 Baseline features of the participants

\begin{tabular}{lllllll}
\hline Studies & $\begin{array}{l}\text { Age (years) } \\
\text { ST/LT }\end{array}$ & $\begin{array}{l}\text { Males (\%) } \\
\text { ST/LT }\end{array}$ & $\begin{array}{l}\text { HBP (\%) } \\
\text { ST/LT }\end{array}$ & $\begin{array}{l}\text { DL (\%) } \\
\text { ST/LT }\end{array}$ & $\begin{array}{l}\text { DM (\%) } \\
\text { ST/LT }\end{array}$ & $\begin{array}{l}\text { CS (\%) } \\
\text { ST/LT }\end{array}$ \\
\hline I LOVE IT 2 & $60.4 / 60.0$ & $62.7 / 68.7$ & $61.0 / 64.8$ & $25.3 / 23.4$ & $23.2 / 22.1$ & $36.6 / 38.3$ \\
IVUS-XPL & $63.0 / 64.0$ & $67.0 / 70.0$ & $63.0 / 65.0$ & $68.0 / 65.0$ & $36.0 / 37.0$ & $25.0 / 24.0$ \\
OPTIMA-C & $62.8 / 64.4$ & $70.0 / 67.8$ & $62.4 / 63.9$ & $29.9 / 28.5$ & $29.1 / 29.7$ & $26.9 / 26.9$ \\
RESET & $62.4 / 62.4$ & $64.4 / 62.9$ & $62.3 / 61.4$ & $57.7 / 59.9$ & $29.8 / 28.8$ & $25.2 / 22.8$ \\
SECURITY & $65.5 / 66.7$ & $71.8 / 74.0$ & $82.5 / 80.3$ & $69.4 / 70.9$ & $100 / 100$ & $33.5 / 35.9$ \\
\hline
\end{tabular}

$H B P$ high blood pressure, $D L$ dyslipidemia, $D M$ diabetes mellitus, $C S$ current smoker, $S T$ short-term DAPT use, $L T$ longterm DAPT use

\section{Main Analytical Results}

A total of 3586 participants with long-term DAPT use were compared with 3556 participants with short-term DAPT use. There was no significant difference in late stent thrombosis associated with short- or long-term DAPT use (OR 0.98, 95\% CI 0.30-3.18; $P=0.97, I^{2}=0 \%$ ) as shown in Fig. 2.

Very late stent thrombosis was also not significantly different (OR 0.30, 95\% CI 0.03-2.95; $P=0.31)$ as shown in Fig. 3 .
Evidence of publication bias reported among the trials that assessed the clinical end points was also low as shown in Fig. 4.

\section{DISCUSSION}

Two major factors contribute to the occurrence of stent thrombosis following PCI: the type of stents being implanted and duration of the antiplatelet regimen after angioplasty. Other factors might include comorbidities such as diabetes mellitus and platelet hyperactivity. 


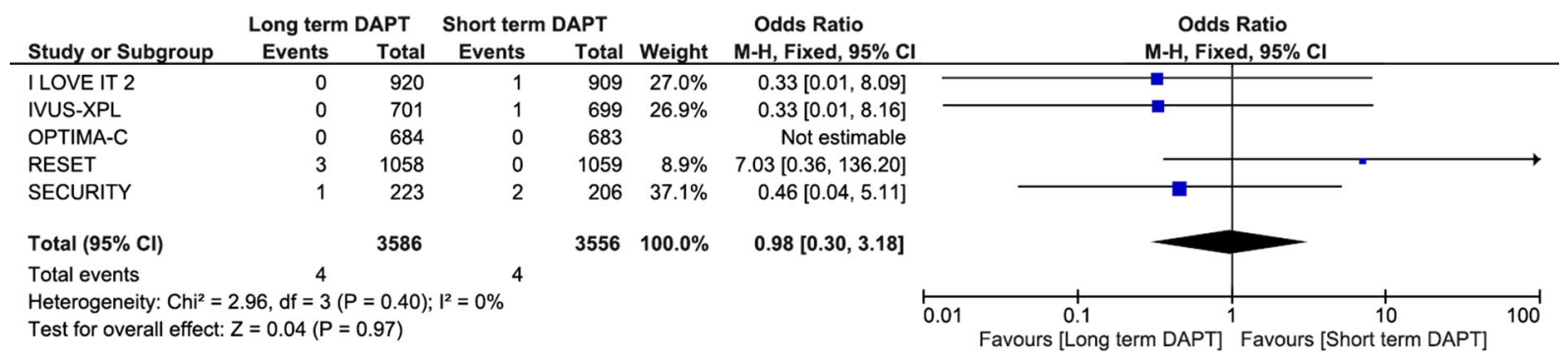

Fig. 2 Comparing the occurrence of late stent thrombosis with a short versus longer duration of DAPT use

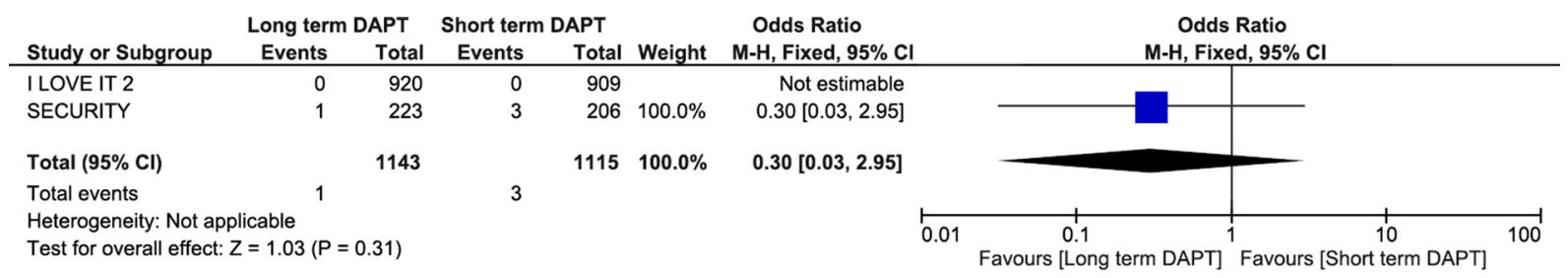

Fig. 3 Comparing the occurrence of very late stent thrombosis with short versus longer duration of DAPT use

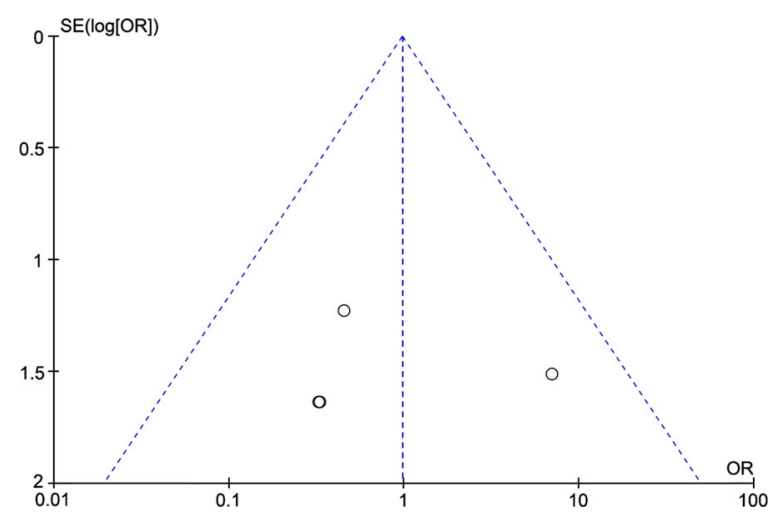

Fig. 4 Publication bias represented in a funnel plot

This simple meta-analysis aimed to show the impact of the duration of DAPT use on the occurrence of late and very late stent thrombosis associated with short- versus long-term DAPT use following PCI with second-generation DES.

Currently, we did not observe any significant difference in late and very late stent thrombosis in a group of patients on short-term (6 months) DAPT versus a group of patients on long-term (12 months) DAPT use following PCI.

Scientific reports have shown second-generation DES to be associated with a significantly lower stent thrombosis rate compared with first-generation DES [13]. However, when EES were compared with ZES (both were second-generation DES), no difference in stent thrombosis was observed [14].

To support the results of this analysis, the International ISAR 2000 All Corner Registry also showed no significant difference in the stent thrombosis rate with short- versus long-term DAPT use following PCI [15]. One out of 165 and 340 participants with short- ( $\leq 6$ months) and long-term ( $>6$ months) DAPT use, respectively, suffered late stent thrombosis. All the participants were diabetes mellitus patients.

The Real Safety and Efficacy of 3-Month Dual Antiplatelet Therapy Following Endeavor ZES Implantation (RESET Trial) also showed no significant difference in stent thrombosis after clopidogrel was stopped following 3-month DAPT use in patients implanted with secondgeneration DES [11].

Even in the Impact of Intravascular Ultrasound Guidance on Outcomes of Xience Prime Stents in Long Lesions (IVUS-XPL) Randomized Clinical Trial in which 1400 patients who were treated with EES were assessed, stent thrombosis was observed in $0.3 \%$ of the patients with a short- and long-term DAPT use, respectively, 
further supporting the results of this analysis [9].

Duration of DAPT use and occurrence of late stent thrombosis are important issues that should be addressed clinically. This current issue has seldom been systematically assessed in clinical research representing a novelty in itself. Findings and analyses with very low heterogeneity were obtained showing the use of good data (extracted from randomized trials) for this systematic analysis. In addition, the total number of participants was not very high, but was at least sufficient to reach a definitive conclusion.

Limitations were the lower number of trials implying a limited number of participants as well as the different follow-up time periods, which might have affected the results. However, since these data were collected from original studies, and there were no other studies that could be included in this analysis taking into account the inclusion and exclusion criteria, we could not overcome this limitation. Moreover, one trial reported a 3-month short-term duration of DAPT use compared with all the other trials, which had a minimum duration of 6 months. Also, different second-generation DES were used.

\section{CONCLUSIONS}

This simple analysis showed no impact of DAPT duration on the occurrence of late and very late stent thrombosis. Similar late and very late stent thromboses were observed with 6- versus 12-month duration of DAPT use following PCI with second-generation DES.

\section{ACKNOWLEDGEMENTS}

Funding. No funding or sponsorship was received for this study or publication of this article.

Authorship. All named authors meet the International Committee of Medical Journal Editors (ICMJE) criteria for authorship for this article, take responsibility for the integrity of the work as a whole, and have given their approval for this version to be published.

Authors' Contributions. The authors Beiyou Lin, Ping Li, Peng Wu, Ri-na Jiang, Pravesh Kumar Bundhun and Mohamad Anis Ahmed were responsible for the conception and design, acquisition of data, analysis and interpretation of data, drafting the initial manuscript and revising it critically for important intellectual content. Bei-you Lin wrote the final draft of the manuscript. All the authors approved the final manuscript as it is.

Disclosures. The authors Bei-you Lin, Ping $\mathrm{Li}$, Peng $\mathrm{Wu}$, Ri-na Jiang, Pravesh Kumar Bundhun and Mohamad Anis Ahmed have nothing to disclose.

Compliance with Ethics Guidelines. This article is based on previously conducted studies and does not contain any studies with human participants or animals performed by any of the authors.

Data Availability. All data and materials used in this research are freely available. References have been provided.

Open Access. This article is distributed under the terms of the Creative Commons Attribution-NonCommercial 4.0 International License (http://creativecommons.org/licenses/ by-nc/4.0/), which permits any noncommercial use, distribution, and reproduction in any medium, provided you give appropriate credit to the original author(s) and the source, provide a link to the Creative Commons license, and indicate if changes were made.

\section{REFERENCES}

1. Zimarino M, Corazzini A, Ricci F, Di Nicola M, De Caterina R. Late thrombosis after double versus single drug-eluting stent in the treatment of coronary bifurcations: a meta-analysis of randomized and observational Studies. JACC Cardiovasc Interv. 2013;6(7):687-95. 
2. Kawecki D, Morawiec B, Dola J, Wanha W, Smolka G, Pluta A, Marcinkiewicz K, Ochała A, NowalanyKozielska E, Wojakowski W. First-versus secondgeneration drug-eluting stents in acute coronary syndromes (Katowice-Zabrze Registry). Arq Bras Cardiol. 2016;106(5):373-81.

3. Neumann FJ, Sousa-Uva M, Ahlsson A, Alfonso F, Banning AP, Benedetto U, Byrne RA, Collet JP, Falk V, Head SJ, Jüni P, Kastrati A, Koller A, Kristensen SD, Niebauer J, Richter DJ, Seferović PM, Sibbing D, Stefanini GG, Windecker S, Yadav R, Zembala MO. 2018 ESC/EACTS Guidelines on myocardial revascularization. EuroIntervention. 2019;14(14):1435-534.

4. Levine GN, Bates ER, Blankenship JC, Bailey SR, Bittl JA, Cercek B, Chambers CE, Ellis SG, Guyton RA, Hollenberg SM, Khot UN, Lange RA, Mauri L, Mehran R, Moussa ID, Mukherjee D, Ting HH, O'Gara PT, Kushner FG, Ascheim DD, Brindis RG, Casey DE Jr, Chung MK, de Lemos JA, Diercks DB, Fang JC, Franklin BA, Granger CB, Krumholz HM, Linderbaum JA, Morrow DA, Newby LK, Ornato JP, Ou N, Radford MJ, Tamis-Holland JE, Tommaso CL, Tracy CM, Woo YJ, Zhao DX. 2015 ACC/AHA/SCAI focused update on primary percutaneous coronary intervention for patients with ST-elevation myocardial infarction: An update of the 2011 ACCF/AHA/SCAI guideline for percutaneous coronary intervention and the 2013 ACCF/AHA guideline for the management of ST-elevation myocardial infarction. J Am Coll Cardiol. 2016;67(10):1235-50.

5. Windecker S, Kolh P, Alfonso F, Collet JP, Cremer J, Falk V, Filippatos G, Hamm C, Head SJ, Jüni P, Kappetein AP, Kastrati A, Knuuti J, Landmesser U, Laufer G, Neumann FJ, Richter DJ, Schauerte P, Sousa Uva M, Stefanini GG, Taggart DP, Torracca L, Valgimigli M, Wijns W, Witkowski A. 2014 ESC/ EACTS guidelines on myocardial revascularization: the task force on myocardial revascularization of the European Society of Cardiology (ESC) and the European Association for Cardio-Thoracic Surgery (EACTS) Developed with the special contribution of the European Association of Percutaneous Cardiovascular Interventions (EAPCI). Eur Heart J. 2014;35(37):2541-619.

6. Higgins JP, et al. Assessing risk of bias in included studies, in Cochrane handbook for systematic reviews of interventions. Oxford: Wiley; 2008. p. 187-241.

7. Liberati A, Altman DG, Tetzlaff J, et al. The PRISMA statement for reporting systematic reviews and meta-analyses of studies that evaluate healthcareinterventions: explanation and elaboration. BMJ. 2009;339:b2700.

8. Han Y, Xu B, Xu K, Guan C, Jing Q, Zheng Q, et al. Six versus 12 months of dual antiplatelet therapy after implantation of biodegradable polymersirolimus-eluting stent: randomized substudy of the I-LOVE-IT 2 trial. Circ Cardiovasc Interv. 2016;9(2):e003145.

9. Hong SJ, Shin DH, Kim JS, Kim BK, Ko YG, Choi D, Her AY, Kim YH, Jang Y, Hong MK; IVUS-XPL Investigators. 6-month versus 12-month dual-antiplatelet therapy following long everolimus-elutingstent implantation: the IVUS-XPL randomized clinical trial. JACC Cardiovasc Interv. 2016;9(14):1438-46.

10. Lee BK, Kim JS, Lee OH, Min PK, Yoon YW, Hong BK, Shin DH, Kang TS, Kim BO, Cho DK, Jeon DW, Woo SI, Choi S, Kim YH, Kang WC, Kim S, Kim BK, Hong MK, Jang Y, Kwon HM. Safety of six-month dual antiplatelet therapy after second-generation drug-eluting stent implantation: OPTIMA-C Randomised Clinical Trial and OCT Substudy. EuroIntervention. 2018;13(16):1923-30.

11. Kim BK, Hong MK, Shin DH, Nam CM, Kim JS, Ko YG, Choi D, Kang TS, Park BE, Kang WC, Lee SH, Yoon JH, Hong BK, Kwon HM, Jang Y; RESETInvestigators. A new strategy for discontinuation of dual antiplatelet therapy: the RESET Trial (REal Safety and Efficacy of 3-month dual antiplatelet Therapy following Endeavor zotarolimus-eluting stent implantation). J Am Coll Cardiol. 2012;60(15):1340-8.

12. Tarantini G, Nai Fovino L, Tellaroli P, Chieffo A, Barioli A, Menozzi A, et al. Optimal duration of dual antiplatelet therapy after second-generation drugeluting stentimplantation in patients with diabetes: the SECURITY (Second-Generation Drug-Eluting StentImplantation Followed By Six- Versus TwelveMonth Dual Antiplatelet Therapy)-diabetes substudy. Int J Cardiol. 2016;15(207):168-76.

13. Bundhun PK, Pursun M, Teeluck AR, Long MY. Are everolimus-eluting stents associated with better clinical outcomes compared to other drug-eluting stents in patients with type 2 diabetes mellitus?: a systematic review and meta-analysis. Medicine (Baltimore). 2016;95(14):e3276.

14. Bundhun PK, Yanamala CM, Huang WQ. Comparing stent thrombosis associated with zotarolimus eluting stents versus everolimus eluting stents at 1 year follow up: a systematic review and metaanalysis of 6 randomized controlled trials. BMC Cardiovasc Disord. 2017;17(1):84.

15. Krackhardt F, Waliszewski M, Rischner J, Piot C, Pansieri M, Ruiz-Poveda FL, Boxberger M, Noutsias M, Ríos XF, Kherad B. Nine-month clinical outcomes in patients with diabetes treated with polymer-free sirolimus-eluting stents and 6-month vs. 12-month dual-antiplatelet therapy (DAPT). Herz 2019;44(5):433-439. 